\title{
Understanding plasticity in irradiated alloys through TEM in situ compression pillar tests
}

\author{
Haozheng J. Qu ${ }^{1}$, Kayla H. Yano ${ }^{2}$, Priyam V. Patki ${ }^{2}$, Matthew J. Swenson ${ }^{3}$, Janelle \\ P. Wharro ${ }^{4, a)}$ (iD \\ ${ }^{1}$ School of Industrial Engineering, Purdue University, West Lafayette, Indiana 47906, USA \\ ${ }^{2}$ School of Materials Engineering, Purdue University, West Lafayette, Indiana 47906, USA \\ ${ }^{3}$ Department of Mechanical Engineering, University of Idaho, Idaho 83844, USA \\ ${ }^{4}$ School of Nuclear Engineering, Purdue University, West Lafayette, Indiana 47906, USA; and School of Materials Engineering, Purdue University, West \\ Lafayette, Indiana 47906, USA \\ a) Address all correspondence to this author. e-mail: jwharry@purdue.edu
}

Received: 29 May 2019; accepted: 16 September 2019

Depth-sensing transmission electron microscopic (TEM) in situ mechanical testing has become widely utilized for understanding deformation in irradiated materials. Until now, compression pillars have primarily been used to study the elastic properties and yield of irradiated materials. In this study, we utilize TEM in situ compression pillars to investigate plastic deformation in two ion-irradiated alloys: $\mathrm{Fe}-9 \% \mathrm{Cr}$ oxide dispersion strengthened (ODS) alloy and nanocrystalline $\mathrm{Cu}-24 \% \mathrm{Ta}$. We develop an algorithm to automate the extraction of instantaneous pillar dimensions from TEM videos, which we use to calculate true stress-strain curves and strain hardening exponents. True stress-strain curves reveal intermitted plastic flow in all specimen conditions. In the Fe-9\% Cr ODS, intermitted plastic flow is linked to strain bursts observed in TEM videos. Low strain hardening or strain softening is observed in all specimen conditions. TEM videos link the strain softening in irradiated Fe9\% $\mathrm{Cr}$ ODS to dislocation cross-slip, and in $\mathrm{Cu}-24 \%$ Ta to grain boundary sliding.

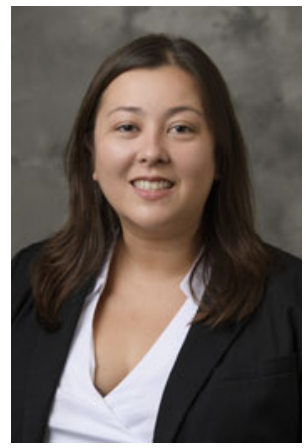

Janelle P. Wharry

\begin{abstract}
Dr. Janelle P. Wharry is an assistant professor in the School of Nuclear Engineering at Purdue University, and also holds a courtesy appointment in the School of Materials Engineering. Dr. Wharry's research focuses on understanding microstructure-property relationships in irradiated materials, with an emphasis on deformation mechanisms and mechanical behavior at the nano/micro scale. Her active projects span nuclear structural and cladding alloys, structural materials produced by advanced manufacturing and joining methods, metal and oxide nuclear fuels, and electroceramic materials. She has published more than 55 peerreviewed articles and proceedings. Dr. Wharry is a recipient of the Department of Energy (DOE) Early Career Award, National Science Foundation CAREER Award, Oak Ridge Associated Universities (ORAU) Ralph E. Powe Junior Faculty Award, and TMS Young Leader Professional Development Award. She is the General Chair of the 2019 Materials in Nuclear Energy Systems (MiNES) Conference, Chair of ASTM International Subcommittee E10.08 on Procedures for Radiation Damage Simulation, invited member of the Nuclear Energy Agency (NEA-OECD) working group on standards for irradiated materials characterization, and former Chair of the American Nuclear Society (ANS) Materials Science \& Technology Division. She received her Ph.D. in Nuclear Engineering \& Radiological Sciences from the University of Michigan in 2012.
\end{abstract}

time video that informs deformation phenomena at SEM/TEM resolutions. The specimen size effect $[4,5,6,7,8,9,10]$ cannot be neglected when reducing mechanical testing geometries to the SEM/TEM scale. The size effect is evidenced by elevated yield stress measurements in successively smaller specimen geometries and is attributed to the specimen geometry being sufficiently small that it contains too few dislocation sources, 
inhibiting plastic yield until a sufficient population of dislocations has been introduced through external loading. However, the presence of irradiation-induced defects and/or nanostructuring sufficiently reduce the intrinsic dimension (i.e., microstructure) of the material, such that an electron-transparent extrinsic dimension (i.e., specimen geometry) can provide meaningful mechanical tests using the in situ TEM approach [11].

A variety of in situ TEM specimen geometries have been demonstrated on irradiated materials, including indentation [12], tensile [13, 14], bending and fracture [15], and compression pillars $[16,17,18,19,20]$. Uniaxial compression pillars are among the most commonly used specimen geometries because their stress state is relatively easy to understand compared to indentation, and they are relatively easy to fabricate as compared to tensile, bend, and fracture geometries [2]. Kiener et al. [16] published the first TEM in situ compression pillar study on an irradiated material. That work investigated the minimum pillar dimensions that would provide meaningful mechanical test results (i.e., representative of bulk mechanical test results) from irradiated $\mathrm{Cu}$. Subsequently, several groups have utilized the approach to quantitatively understand deformation in a number of materials. Dillon and coworkers have used TEM in situ compression pillars to study shear strengths of irradiated $\mathrm{Cu}-\mathrm{Nb}$ interfaces [17] as well as the behavior of irradiation-induced creep in Ag [19]. Yano et al. [18] and Patki [20] have used TEM in situ compression pillars to understand yield strength in irradiated $\mathrm{Fe}-9 \% \mathrm{Cr}$ oxide dispersion strengthened (ODS) and nanocrystalline $\mathrm{Cu}-24 \% \mathrm{Ta}$ alloys, respectively.

The TEM in situ compression pillar studies on irradiated materials have thus far focused primarily on elastic and yield properties (with the exception of the irradiation-induced creep study, Ref. 19), the measurement of which is relatively straightforward. Engineering stress-strain curves are simple to generate from load-displacement data collected from in situ TEM since they require knowledge of only the initial specimen dimensions and cross-sectional area. Subsequently, properties such as yield strength and elastic modulus can be measured directly from the engineering stress-strain curve [18]. But beyond the elastic and yield properties from engineering stressstrain curves, TEM in situ mechanical testing has the potential to enhance our understanding of plastic phenomena which are critical to comprehensively evaluating irradiated materials performance. Studying plastic phenomena (e.g., work hardening) is more complex and requires an understanding of true stress-strain behavior. Generating these true stress-strain curves can be challenging because they require knowledge of the instantaneous specimen dimensions throughout loading.

With the widespread adoption of nano-/micro-mechanical materials testing techniques over the past decade, numerous methods have been developed to generate true stress-strain curves and measure local stresses and strains from SEM or
TEM in situ videos, recently summarized in Ref. 21. Many of these methods are based on digital image correlation (DIC) techniques $[22,23,24,25]$. Specifically, a photogrametric pixelbased pattern recognition algorithm is used, which maps the microtexture onto a finite element mesh [26]. This requisite coupling with a finite element model is critical for mapping stresses and strains across a microstructure. However, there remains an opportunity for generating a true stress-strain curve in a simpler, self-contained, and more automated manner.

In this paper, we present an automated method for processing TEM in situ micropillar compression test videos to extract the instantaneous pillar dimensions and then determine the true stress-strain curves. This method is benchmarked for the TEM in situ micropillar compression tests previously published by the authors on as-received and ionirradiated model Fe-9\% Cr ODS alloy and nanocrystalline $\mathrm{Cu}-$ $24 \% \mathrm{Ta}$. The strain hardening coefficients are extracted from the true stress-strain curves and are discussed in the context of the deformation mechanisms observed concurrently in the TEM in situ videos.

\section{Results}

\section{Summary of elastic and yield properties from compression pillar tests}

TEM in situ compression pillars were used to measure the elastic properties, including modulus and yield strength, of the as-received, 3 and 100 dpa-irradiated Fe-9\% Cr ODS [18]. Elastic moduli measured directly from the TEM in situ compression tests were adjusted for deformation and deflection in the base material and then fell within a range of 130-309 $\mathrm{GPa}$, consistent with the expected values [18]. Irradiation had little to no effect on the elastic modulus [18]. Compression yield stress values were also relatively unaffected by irradiation [18] and were consistent with the expected values for minimum pillar dimensions larger than $\sim 100 \mathrm{~nm}$ [27]. The $\mathrm{Cu}-24 \% \mathrm{Ta}$ compression yield stress values were also unchanged with $1 \mathrm{dpa}$ irradiation [20]. All pillars, even those with external dimensions $\leq 100 \mathrm{~nm}$, have yield stresses near the expected bulk yield stress because of the $\sim \mathrm{nm}$ scale of the $\mathrm{Cu}-24 \%$ Ta microstructure [11].

The absence of statistically significant irradiation strengthening in both the ODS and $\mathrm{Cu}-24 \%$ Ta was consistent with the observed microstructure stability in both materials and can be explained by the enhanced kinetics at the $500{ }^{\circ} \mathrm{C}$ irradiation temperature. Negligible irradiation hardening is typical of $500{ }^{\circ} \mathrm{C}$ irradiations in a variety of $\mathrm{Fe}-\mathrm{Cr}$ alloys including a model Fe-9 Cr alloy self-ion irradiated to 1 dpa [28], F82H irradiated with $\mathrm{Fe}^{3+}$ to 5 dpa [29], tempered martensitic HT-9 proton irradiated to $2 \mathrm{dpa}$ [30], and T91 proton irradiated to 3 dpa [31]. 


\section{True stress-strain curves and strain hardening exponents}

To gain insight into plastic deformation, true stress-strain curves are generated for each compression pillar experiment using the algorithm described in section "True stress-strain curves and strain hardening exponents." with "Algorithm to automate true stress-strain calculation." Representative pairs of engineering and true stress-strain curves are shown for each material condition in Figs. 1 and 2 for the ODS and $\mathrm{Cu}-24 \% \mathrm{Ta}$, respectively. The true stress-strain curves are identical to the engineering stress-strain curves through the elastic region, but the curves deviate from one another upon plastic yielding. The pillar barreling (i.e., increasing pillar width and thickness) during plasticity causes the true stresses to be lower than engineering stresses, and true strains to be larger than engineering strains. As is common in nanosized pillars and wires, the stress-strain curves tend to exhibit three regions: (i) linear elastic, (ii) strain hardening immediately upon plastic yielding, and (iii) plastic yielding at constant or gradually decreasing flow stress [32, 33]. These three distinct regions, marked in Fig. 2(a) as an example, are more clearly evident in the true than in the engineering stress-strain curves.
The strain hardening (or softening) exponent, $\mathrm{n}$, describes the deformation characteristics of a material and is obtained from the true stress-strain curves. The Matlab ${ }^{\text {rx }}$ algorithm developed herein uses linear regression to calculate the strain hardening exponent based on the user-identified strain range of interest:

$$
\begin{gathered}
\sigma=K \varepsilon^{n}, \\
\log (\sigma)=n \times \log (\varepsilon)+\log (K) .
\end{gathered}
$$

In the $\mathrm{Fe}-9 \% \mathrm{Cr}$ ODS, the as-received pillars tend to exhibit low but positive strain hardening exponents, with an average value of 0.16 . But after irradiation, the average strain hardening exponents are reduced and become negative, with average values of -0.21 and -0.25 for the $3 \mathrm{dpa}$ and $100 \mathrm{dpa}$ specimens, respectively. Hence, irradiation induces strain softening in the $\mathrm{Fe}-9 \% \mathrm{Cr}$ ODS. In the $\mathrm{Cu}-24 \% \mathrm{Ta}$, on the other hand, strain hardening coefficients are negative even in the as-received material (average value -0.21). Irradiation does not measurably alter the strain hardening coefficient for $\mathrm{Cu}-$ $24 \% \mathrm{Ta}$ (average value -0.24 ), and the strain softening
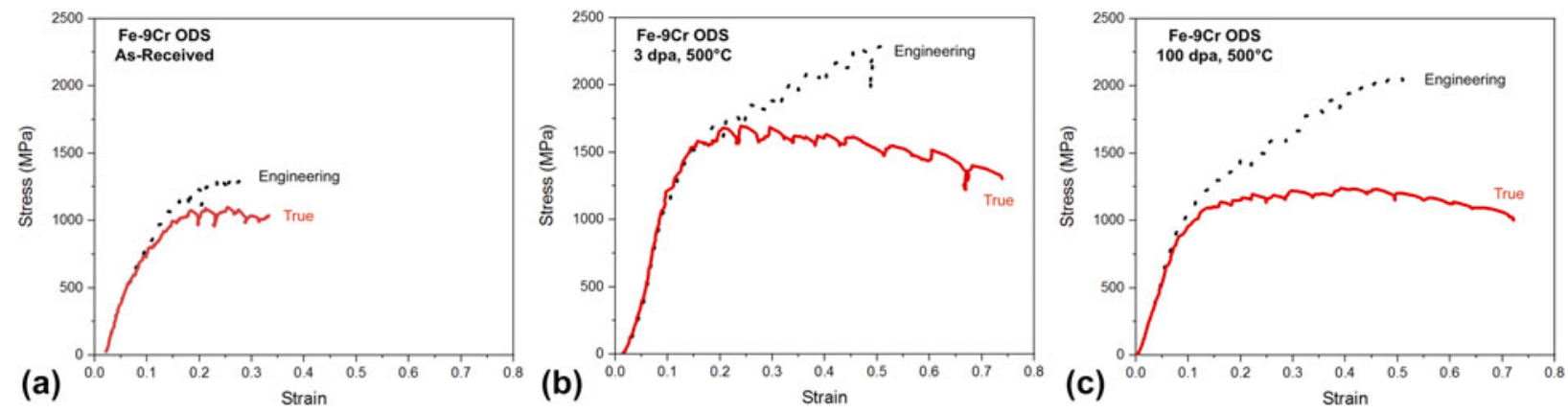

Figure 1: Representative engineering (dashed) and true (solid) stress-strain curves from (a) as-received, (b) 3 dpa, and (c) 100 dpa Fe-9\% Cr ODS micropillars.
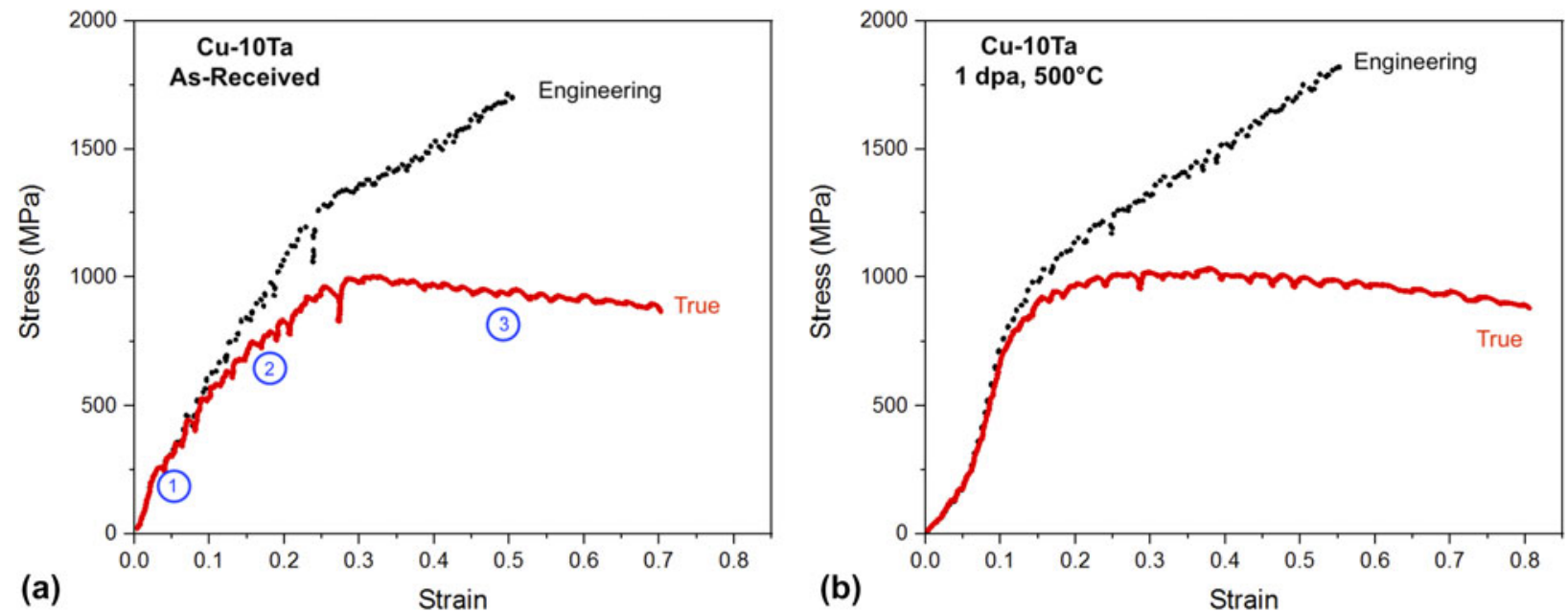

Figure 2: Representative engineering (dashed) and true (solid) stress-strain curves from (a) as-received and (b) $1 \mathrm{dpa}$ Cu-24\% Ta micropillars. 
behavior persists. Strain hardening exponents of both the Fe-9 $\mathrm{Cr}$ ODS and $\mathrm{Cu}-24 \% \mathrm{Ta}$ appear to be independent of strain rate, at least within the narrow strain rate range tested, 0.005$0.025 \mathrm{~s}^{-1}$ (Fig. 3). Meanwhile, the strain hardening exponent for $\mathrm{Fe}-9 \mathrm{Cr}$ ODS is dependent on the specimen minimum dimension, Fig. 3(c), although this trend does not hold for the $\mathrm{Cu}-24 \%$ Ta [Fig. 3(d)].

\section{TEM video}

The true stress-strain curves also obviate the numerous load drops that occur throughout deformation in both as-received and irradiated alloys. In the Fe-9\% Cr ODS, load drops appear to be associated with dislocation bursts. One such burst is depicted in still-frames from the TEM resolution video of the as-received $\mathrm{Fe}-9 \% \mathrm{Cr}$ ODS [Figs. 4(a)-4(c)], in which a band of dislocations moves through the material at time coincident with a load drop in the true stress-strain curve. But with irradiation, possible dislocation cross-slip is observed in Fe-9\%
Cr ODS. Specifically, 'U'-shaped dislocations moving upward [one such dislocation is identified with an arrow in Figs. 4(d) and $4(\mathrm{e})]$ cross-slip and become lines moving northwest [Figs. 4(f) and $4(\mathrm{~g})$ ].

In the $\mathrm{Cu}-24 \% \mathrm{Ta}$, the load drops are believed to be associated with grain boundary sliding events. For example, in the irradiated $\mathrm{Cu}-24 \% \mathrm{Ta}$, still-frames from the TEM video show grain boundary sliding at a triple junction [Figs. 5(a)-5(c)] following dislocation-mediated triple junction displacement that is characteristic of grain boundary sliding [34]. Two of the three boundaries comprising the triple junction exhibit sliding, with each boundary's motion corresponding to a load drop in the true stress-strain curve [Fig. 5(d)].

\section{Discussion}

Bulk compression tests for the $\mathrm{Cu}-24 \%$ Ta show a small amount of strain hardening at the onset of plasticity, followed
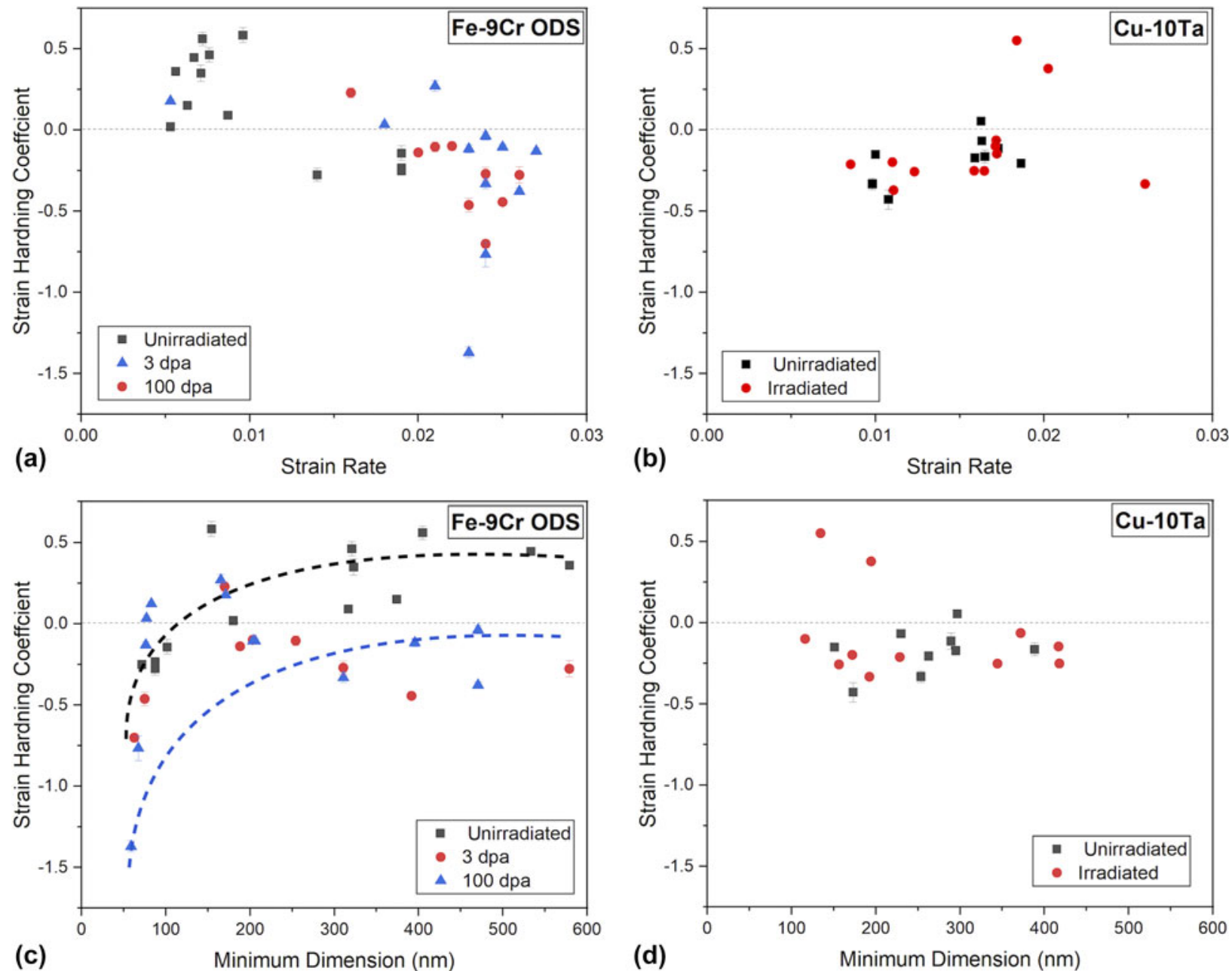

Figure 3: Strain hardening exponent as a function of strain rate for (a) ODS and (b) Cu-24\% Ta, and as a function of minimum pillar dimension for (c) ODS and (d) $\mathrm{Cu}-24 \% \mathrm{Ta}$. 

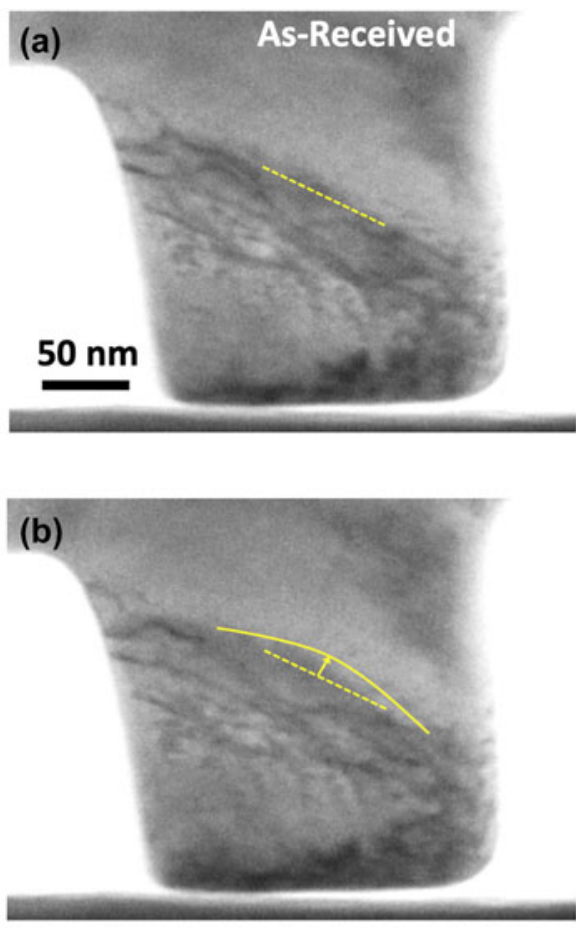

(c)

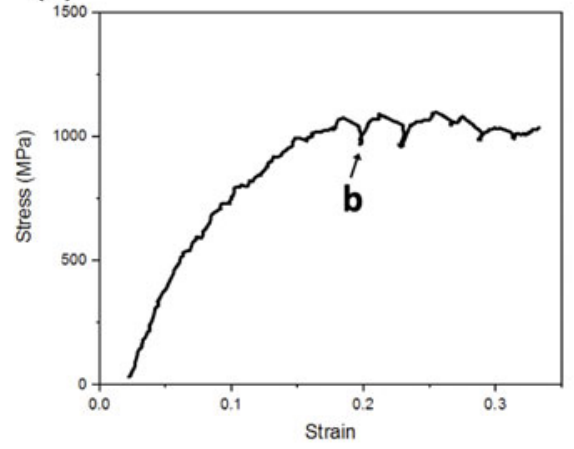

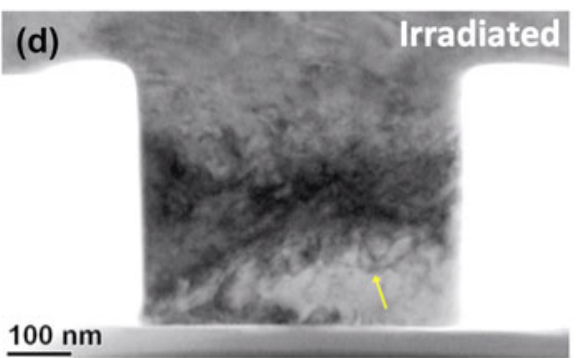
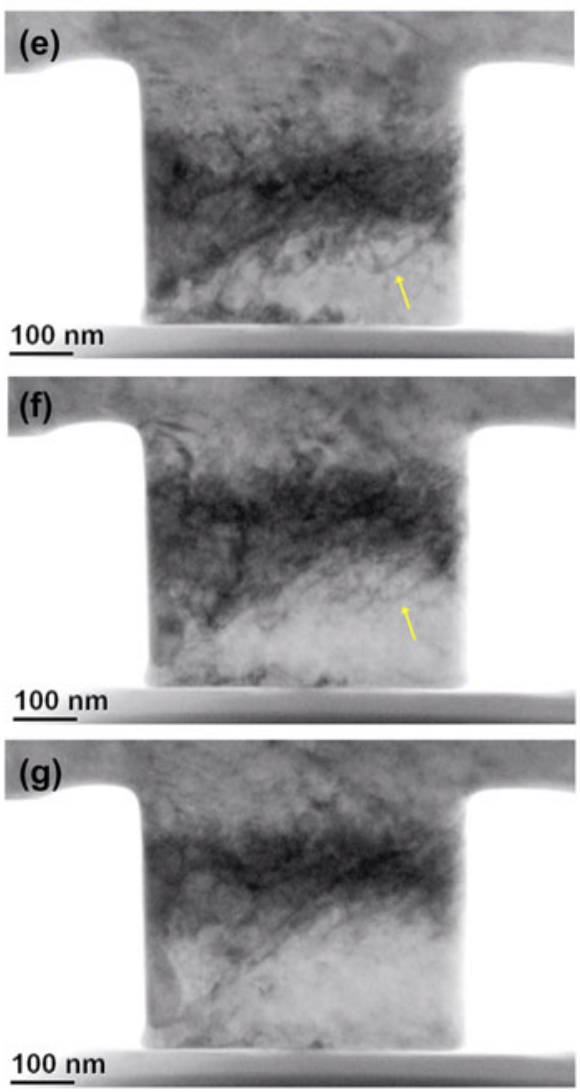

Figure 4: Still-frames from TEM in situ compression pillar test on as-received Fe-9\% $\mathrm{Cr}$ ODS, showing strain burst (a and b) corresponding to load drops on the true stress-strain curve (c); and still-frames from TEM in situ compression pillar test on $3 \mathrm{dpa}, 500{ }^{\circ} \mathrm{C}$, $\mathrm{Fe}^{2+}$ irradiated Fe-9\% $\mathrm{Cr}$ ODS, showing dislocation in (d and e) cross-slipping in (f and g).

by pronounced strain softening [35]. This complex behavior is relatively consistent with the generally negative strain hardening coefficients measured from as-received and irradiated $\mathrm{Cu}-$ 24\% Ta compression pillars herein. Likewise, the strain hardening coefficients from most of the as-received Fe-9\% Cr ODS pillars fall reasonably near the bulk values of $\sim 0.2-0.4$ as measured by nanoindentation in Refs. 36 and 37 . However, the strain hardening coefficients from the irradiated $\mathrm{Fe}-9 \% \mathrm{Cr}$ ODS pillars are notably lower than bulk values. But it is well known that nano- through micro-scale mechanical tests are currently unable to extract meaningful "bulk" hardening parameters [38]. The miniaturized specimen geometry [39, 40] and the microstructure-controlled localized plastic phenomena most significantly influence the strain hardening coefficient measured in nano-/micro-mechanical tests. These factors will be considered in the remainder of this section.

\section{Intermitted plastic flow}

Intermitted stress-strain curves, with load drops associated with isolated slip events or strain bursts, are well known to occur during deformation of nano- through micro-scale specimens [41]. These isolated strain bursts in microcompression pillars have also been linked to strain softening [42]. Low strain hardening exponents and strain softening are also common in materials undergoing localized deformation [43]; this behavior tends to be exacerbated with irradiation [44]. Strain softening due to strain localization has been observed and predicted in 


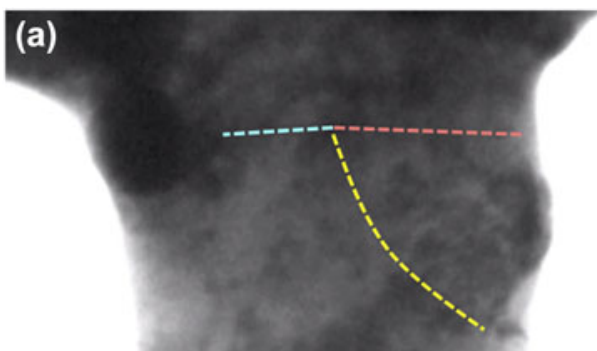

\section{$100 \mathrm{~nm}$}
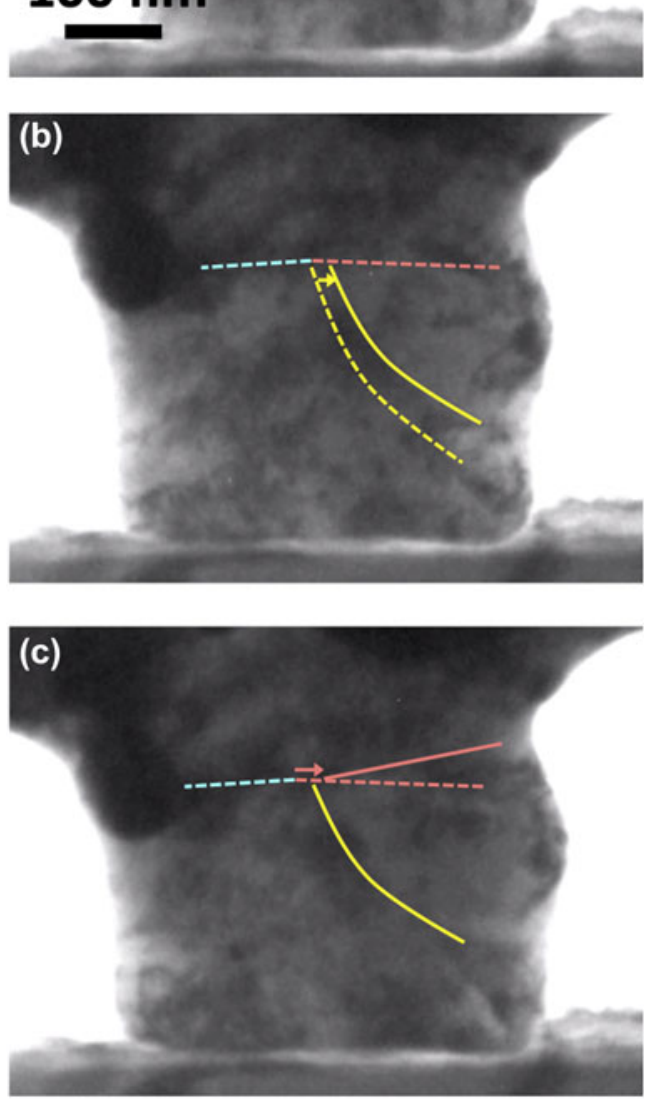

(d)

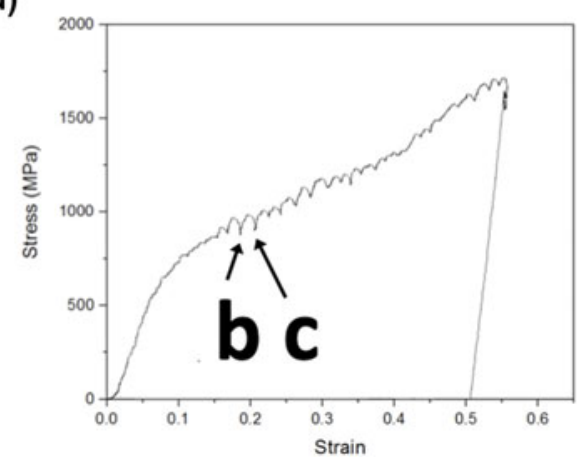

Figure 5: (a-c) Still-frames from TEM in situ compression pillar test on $1 \mathrm{dpa}$, $500{ }^{\circ} \mathrm{C}$ proton-irradiated $\mathrm{Cu}-24 \% \mathrm{Ta}$, showing two-step grain boundary sliding of the yellow (b) and pink (c) boundaries at a triple junction, corresponding to load drops on the engineering stress-strain curve (d).

a wide variety of irradiated materials including Fe and steels [44, 45], Zr alloys [44], $\mathrm{Cu}$ [46], Mo [47], Ni [48], and $\mathrm{Au}$ [48].
Likewise, in unirradiated materials, low strain hardening or strain softening due to localized deformation has been observed in materials prehardened by cold working [49, 50, 51, 52], quenching $[51,53]$, or precipitation $[53,54]$, which tend to have the effect of locking dislocations and dislocation sources. Strain burst-based load drops during deformation are consistent with observations from the TEM video collected during the Fe-9\% Cr ODS compression tests (Fig. 4). These load drops typically occur when dislocation sources, once activated, send avalanches of dislocations through the material. These avalanches sweep out the barriers ahead of them, clearing a soft pathway resulting in strain softening [52]. Other proposed explanations include rapid dislocation release and movement [55], cascade-induced source hardening [56], and geometrical softening [57].

\section{Strain softening}

The microstructure is believed to be central to the strain hardening/softening behavior in the as-received and irradiated Fe-9\% Cr ODS. Dislocation dynamics models have provided plausible explanations for both oxide nanocluster-induced strain hardening and strain softening. For example, incoherent oxide nanoclusters cause strain hardening as mobile dislocations pinch off into Orowan loops around them [58]. On the other hand, incoherent oxide nanoclusters can also force mobile dislocations to cross-slip around them [59], resulting in little strain hardening. Both of these explanations could be at work in the as-received $\mathrm{Fe}-9 \% \mathrm{Cr}$ ODS, justifying the low strain hardening measured.

Irradiation induces strain softening in the Fe-9\% Cr ODS, which can be attributed to irradiation-induced oxide disordering and dislocation loop nucleation and growth. We have shown that the oxide nanoclusters in the same 3- and 100-dpa specimens studied herein undergo inverse Ostwald ripening during irradiation [60]. Inverse Ostwald ripening occurs due to competing irradiation damage mechanisms of ballistic dissolution and diffusion-driven nanocluster growth [61]. In the most extreme cases, inverse Ostwald ripening is evidenced by a reduced average cluster size and increased number density, but during its evolutionary stages, the phenomenon presents as enhanced incoherency, disordering, irregularity, or "haloing" at the oxide-matrix interface $[62,63,64]$. As these oxide-matrix interfaces become increasingly diffuse and incoherent, dislocation cross-slip around them becomes more likely and common [59], further reducing strain hardening. Another theory from Robertson and Gururaj [59] considers the concomitant roles of oxide nanoclusters and irradiation-induced dislocation loops. In the presence of loops, dislocations accumulate around oxides, generating high internal stresses and leading to crossslip. With the help of internal stresses, cross-slipped 
dislocations can then overcome dislocation loops, reducing strain hardening. This can explain the possible cross-slip behavior observed in the TEM in situ compression video of the irradiated $\mathrm{Fe}-9 \% \mathrm{Cr}$ ODS (Fig. 4). Our prior TEM in situ indentation tests [12] also corroborate the idea that dislocation loops play a central role in deformation of the same irradiated $\mathrm{Fe}-9 \% \mathrm{Cr}$ ODS studied here.

The low strain hardening and strain softening observed in the $\mathrm{Cu}-24 \% \mathrm{Ta}$ specimens are typical of nanostructured and nanocrystalline materials $[65,66,67]$ because nanocrystalline grains are inherently unable to accumulate dislocations, unless dislocation motion can be obstructed through pinning, tangling, or locking [68]. Rather, in nanocrystalline materials, grain boundary dislocation emission and absorption occur readily because of the high number density of grain boundaries $[69,70,71,72]$, leading to deformation by grain boundary sliding and migration $[73,74,75,76,77]$ or grain rotation $[72$, $78,79,80,81,82,83]$. Similarly, micropillar compression and nanoindentation studies of $\mathrm{Al} / \mathrm{Al}_{3} \mathrm{Sc}$ [84], $\mathrm{Al} / \mathrm{Nb}$ [85], $\mathrm{Cu} / \mathrm{Zr}$ [86], and $\mathrm{Cu} / \mathrm{Nb}[87,88]$ nanolayers exhibit strain softening when nanolayer thicknesses are on the order of a few tens of $\mathrm{nm}$. Dislocation emission and absorption readily occur at nanolayer interfaces, with little to no dislocation accumulation within the layers. The softening is subsequently attributed to slip on the interlayer planes [87].

These typical mechanisms of strain softening are consistent with the evidence of grain boundary sliding shown in our irradiated Cu-24\% Ta TEM in situ compression pillars (Fig. 5). The absence of an irradiation-induced change in strain hardening exponent for $\mathrm{Cu}-24 \% \mathrm{Ta}$ is consistent with the negligible irradiation-induced microstructure evolution [20]. Hence, the extreme irradiation tolerance attributed to the nanocrystallinity of the $\mathrm{Cu}-24 \% \mathrm{Ta}$ limits the extent of structure-property evolution under irradiation.

\section{Parametric dependences of strain hardening exponents}

The observation that strain hardening exponents are independent of strain rate (Fig. 3) is consistent with arguments presented by Dunstan and Bushby [39] and Kiener and Minor [40], which state that the parameters that most strongly influence strain hardening exponent are the specimen geometry and the flow strain. It is expected that the strain hardening exponent for $\mathrm{Fe}-9 \mathrm{Cr}$ ODS will be dependent on the specimen minimum dimension [Fig. 3(c)]. The size effect on strain hardening can be explained because at very small specimen dimensions, there are insufficient defects in the material-so once dislocations are nucleated, they can glide easily without getting hung up on defects, hence the absence of the typical work hardening behavior. But the observed independence of the $\mathrm{Cu}-24 \% \mathrm{Ta}$ strain hardening exponent on the specimen dimension [Fig. 3(d)] is believed to be caused by the extremely nanoscopic characteristic length of the microstructure $(\sim 20 \mathrm{~nm})$ [11], which is smaller than even the smallest pillar dimensions tested $(\sim 75 \mathrm{~nm})$. The same phenomenon has been observed for the $\mathrm{Cu}-24 \%$ Ta yield stress measured by TEM in situ compression pillars, in which an absence of a transition between size-effected and "bulk-like" yield stresses was observed [11] due to the nanoscopic characteristic length, i.e., intrinsic size, of the microstructure.

\section{Conclusions}

We have analyzed the plastic deformation of as-received and irradiated $\mathrm{Fe}-9 \% \mathrm{Cr}$ ODS and nanocrystalline $\mathrm{Cu}-24 \% \mathrm{Ta}$, following TEM in situ compression pillar testing. We have developed an algorithm to automate the measurement of instantaneous pillar dimensions, which enabled us to generate true stress-strain curves for each pillar. Intermitted plastic flow is observed in all as-received and irradiated specimens of both $\mathrm{Fe}-9 \% \mathrm{Cr}$ ODS and $\mathrm{Cu}-24 \% \mathrm{Ta}$. This behavior is typical of nano- through micro-scale specimens and is directly linked to strain bursts in the $\mathrm{Fe}-9 \% \mathrm{Cr}$ ODS as observed in TEM videos.

Strain hardening coefficients were calculated for each pillar. Values of the strain hardening exponent were low to negative for all specimen conditions, indicative of low strain hardening to strain softening. In $\mathrm{Fe}-9 \% \mathrm{Cr}$ ODS, irradiation induces strain softening due to the irradiation-induced disordering of oxide nanoclusters and nucleation of dislocation loops. In the $\mathrm{Cu}-24 \% \mathrm{Ta}$, the strain softening is attributed to grain boundary sliding, which is directly observed in the TEM videos during compression testing. Strain hardening exponents are generally independent of strain rate, but are influenced by specimen dimensions.

\section{Methods}

\section{Materials, irradiations, and micropillar compression testing}

This work analyzes the stress-strain response of TEM in situ compression pillars of two irradiated nanostructured alloys: an Fe-9\% Cr ODS steel and a Cu-24\% Ta nanocrystalline alloy (compositions in wt\%). Here, we will summarize the materials, their irradiations, and their microstructures.

The Fe-9\% Cr ODS was obtained from the Japan Nuclear Fuel Cycle Development Institute (now known as the Japan Atomic Energy Agency). The ODS alloy was processed by mechanical alloying of ferritic steel with $\mathrm{Y}_{2} \mathrm{O}_{3}$ powder, followed by $1150^{\circ} \mathrm{C}$ hot extrusion. The final heat treatment involved $1-\mathrm{h}$ solutionizing at $1050{ }^{\circ} \mathrm{C}$, air cooling, $800{ }^{\circ} \mathrm{C}$ tempering, and a final air cooling. The composition in wt\% of major 
components is $\mathrm{Fe}-8.67, \mathrm{Cr}-1.96, \mathrm{~W}-0.23$, Ti-0.27, $\mathrm{Y}-0.14$, O$0.14, \mathrm{C}-0.34$, and $\mathrm{Y}_{2} \mathrm{O}_{3}$. Complete details of the fabrication and processing of the ODS alloy can be found in Ref. 89. Specimens of the ODS alloy were irradiated with $5.0 \mathrm{MeV} \mathrm{Fe}{ }^{2+}$ ions to doses of 3 and 100 displacements per atom (dpa) at $500{ }^{\circ} \mathrm{C}$. To achieve these doses, total ion fluences of $4.0 \times 10^{15}$ and $1.3 \times$ $10^{17}$ ions $/ \mathrm{cm}^{2}$ were delivered, respectively, at a dose rate of 2.2 $\times 10^{-4} \mathrm{dpa} / \mathrm{s}$. The irradiation damage profile was calculated using the Stopping Range of Ions in Matter (SRIM) 2013 in quick Kinchin-Pease mode, per Ref. 90. The nominal doses of 3 and 100 dpa were determined at a depth of 400-600 nm into the damage profile, which avoids both surface and ion implantation effects as recommended by Zinkle and Snead [91]. Comprehensive irradiation experiment details can be found in Refs. 18 and 36.

The starting microstructure of the ODS alloy is comprised of $\sim 230 \mathrm{~nm}$ fully martensitic grains containing a dislocation density of $\sim 19 \times 10^{14} \mathrm{~m}^{-2}$ and $\sim 6 \mathrm{~nm}$ oxide nanoclusters at a number density of $\sim 57 \times 10^{22} \mathrm{~m}^{-3}$ [92]. There are no statistically significant irradiation-induced changes in grain size and dislocation density [60, 93]. However, both the 3- and 100dpa irradiations induce the nucleation of $\sim 10 \mathrm{~nm}$ dislocation loops at number densities on the order of $\sim 10^{21} \mathrm{~m}^{-3}$. The oxide nanocluster number density decreases by a factor of four in the 3 -dpa irradiation condition $[60,93]$. The comprehensive microstructure quantification from Refs. 60 and 93 is summarized in Table I, with example micrographs shown in Figs. 6(a) and 6(b).

The $\mathrm{Cu}-24 \% \mathrm{Ta}$ is a binary nanocrystalline alloy, studied as a simple model system of engineering ODS alloys. The $\mathrm{Cu}-24 \%$ Ta was obtained from the US Army Research Laboratory and was synthesized by high-energy cryogenic mechanical alloying of immiscible $\mathrm{Cu}$ and Ta powders. As-milled powders were consolidated by equal channel angular extrusion (ECAE) at $700{ }^{\circ} \mathrm{C}$ using a channel angle of $90^{\circ}$. Four consecutive extrusions produced a total strain of $\sim 450 \%$ in the material. Comprehensive details on the $\mathrm{Cu}-24 \%$ Ta alloy processing are available in Ref. 35. The as-extruded microstructure contains $\sim 70 \mathrm{~nm}$ metallic $\mathrm{Cu}$ grains, with a bimodal metallic Ta particle size distribution having mean values around 7 and $40 \mathrm{~nm}$ [35]. The $\mathrm{Cu}-24 \%$ Ta was irradiated with $2.0 \mathrm{MeV}$ protons to $1 \mathrm{dpa}$ at $500{ }^{\circ} \mathrm{C}$. To achieve this dose, a total ion fluence of $7.6 \times 10^{18}$ protons $/ \mathrm{cm}^{2}$ was delivered, and the dose rate was $7.3 \times 10^{-5}$ $\mathrm{dpa} / \mathrm{s}$. The irradiation damage profile was calculated using SRIM 2013 in quick Kinchin-Pease mode, and the nominal dose of 1 dpa was determined at a depth of $10 \mu \mathrm{m}$ (i.e., approximately half the distance to the damage peak). The $\mathrm{Cu}-24 \% \mathrm{Ta}$ was irradiated concurrently with specimens analyzed in Ref. 94, which provides more comprehensive details of the proton irradiation experiments. No statistically significant grain or phase size evolution was observed after irradiation, and sparse irradiation-induced defects were reported in the $\mathrm{Cu}$ grains [20]. The microstructure quantification is summarized in Table I, with example micrographs in Figs. 6(c) and 6(d). The chemical composition of $\mathrm{Cu}$ grains and Ta phases and nanoclusters is confirmed using energy filtered TEM (EFTEM), Figs. 6(e) and 6(f).

Micropillars having rectangular cross-sections were fabricated from the as received and irradiated Fe-9\% Cr ODS and $\mathrm{Cu}-24 \%$ Ta using focused ion beam (FIB) milling. Micropillar dimensions were systematically varied between 60 and $700 \mathrm{~nm}$ to understand the role of extrinsic size effects. Corners and edges of pillars having rectangular cross-sections are known to introduce stress concentrations that influence elastic properties and yield stress [40,95]. But since the present work focuses on the plastic region of the stress-strain curve, stress concentrations at pillar corners and edges are not considered in the strain hardening analysis. The external dimensions were verified by TEM and thickness by electron energy loss spectroscopy (EELS). A minimum of 10 micropillars were tested from each material

TABLE I: Quantitative summary of microstructure of materials tested.

\begin{tabular}{|c|c|c|c|c|c|c|}
\hline \multirow[b]{2}{*}{ Feature } & \multirow[b]{2}{*}{ Measurement } & \multicolumn{3}{|c|}{$\mathrm{Fe}-9 \% \mathrm{Cr}$ ODS } & \multicolumn{2}{|c|}{$\mathrm{Cu}-24 \% \mathrm{Ta}$} \\
\hline & & As-received [92] & $3 \mathrm{dpa}, 500{ }^{\circ} \mathrm{C}[18]$ & $100 \mathrm{dpa}, 500^{\circ} \mathrm{C}[18]$ & As-received $[20,35]$ & $1 \mathrm{dpa}, 500{ }^{\circ} \mathrm{C}[20]$ \\
\hline Dislocation lines & Density $\left(\times 10^{14} \mathrm{~m}^{-2}\right)$ & $19.1 \pm 3.8$ & $22.6 \pm 4.8$ & $18.4 \pm 6.9$ & $\ldots$ & $\ldots$ \\
\hline \multirow{2}{*}{ Carbides } & Diameter $(\mu \mathrm{m})$ & $0.11 \pm 0.07$ & $0.08 \pm 0.04$ & $0.08 \pm 0.03$ & $\ldots$ & $\ldots$ \\
\hline & Density $\left(\times 10^{20} \mathrm{~m}^{-3}\right)$ & 0.20 & 0.29 & 0.76 & $\ldots$ & $\cdots$ \\
\hline \multirow[b]{2}{*}{ Dislocation loops } & Diameter (nm) & $\ldots$ & $8.5 \pm 2.2$ & $10.7 \pm 4.2$ & $\ldots$ & $\ldots$ \\
\hline & Density $\left(\times 10^{21} \mathrm{~m}^{-3}\right)$ & $\ldots$ & $2.1 \pm 0.1$ & $4.3 \pm 0.8$ & $\ldots$ & $\ldots$ \\
\hline \multirow[b]{2}{*}{ Oxides } & Diameter (nm) & $5.71 \pm 1.92$ & $5.73 \pm 1.47$ & $5.58 \pm 2.30$ & $\ldots$ & $\ldots$ \\
\hline & Density $\left(\times 10^{21} \mathrm{~m}^{-3}\right)$ & 443 & 120 & 433 & $\ldots$ & $\ldots$ \\
\hline Cu grains & Diameter (nm) & $\cdots$ & $\cdots$ & $\cdots$ & $70 \pm 25$ & $77 \pm 14.76$ \\
\hline \multirow{2}{*}{ Larger Ta phases } & Diameter (nm) & $\ldots$ & $\ldots$ & $\ldots$ & $40 \pm 15$ & $109 \pm 74$ \\
\hline & Density $\left(\times 10^{19} \mathrm{~m}^{-3}\right)$ & $\ldots$ & $\cdots$ & $\ldots$ & 4.66 & 5.8 \\
\hline \multirow{2}{*}{ Smaller Ta phases } & Diameter (nm) & $\ldots$ & $\ldots$ & $\ldots$ & $3.75 \pm 0.09$ & $3.87 \pm 0.17$ \\
\hline & Density $\left(\times 10^{22} \mathrm{~m}^{-3}\right)$ & $\ldots$ & $\ldots$ & $\ldots$ & 65 & 8.5 \\
\hline
\end{tabular}



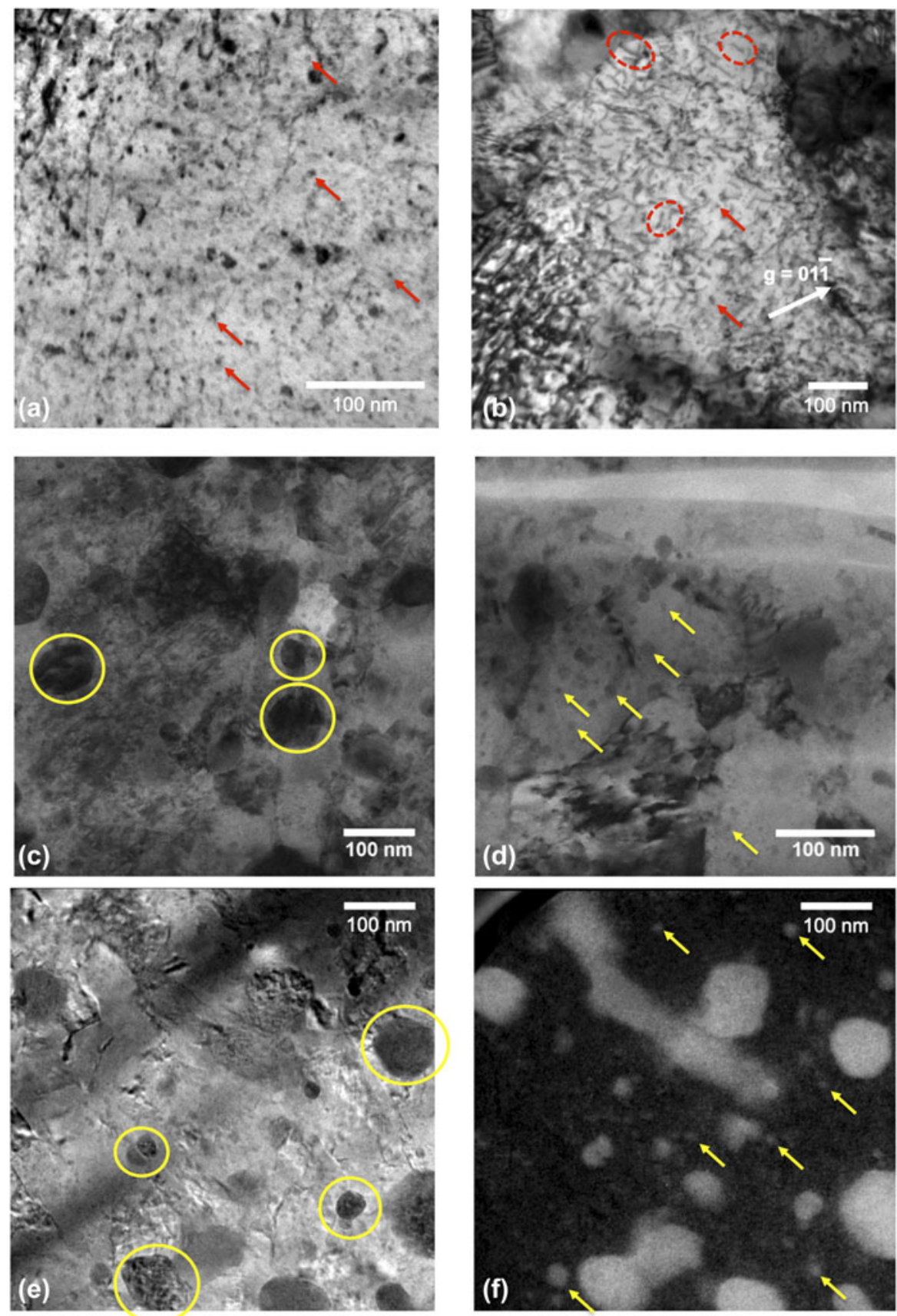

Figure 6: Representative bright-field TEM micrographs of (a) as-received and (b) irradiated Fe-9\% $\mathrm{Cr}$ ODS, with red arrows indicating oxide nanoclusters and dashed red circles indicating dislocation loops; and (c) as-received and (d) irradiated Cu-24\% Ta, with yellow arrows indicating Ta nanoclusters $\lesssim 20 \mathrm{~nm}$ and solid yellow circles indicating Ta phases $\gtrsim 20 \mathrm{~nm}$. Composition of Ta phases and nanoclusters in irradiated Cu-24\% Ta is confirmed by (e) zero loss image and (f) EFTEM.

condition. Micropillars were compressed to half of their original height using a diamond flat punch tip on a Hysitron (now Bruker, Minneapolis, Minnesota) PI-95 depth-sensing TEM mechanical testing holder. Throughout each compression test, quantitative load and displacement data were collected along with TEM-resolution video at a frame rate of 30 frames per second (fps). Strain rates ranged 0.01-0.026 s $\mathrm{s}^{-1}$. Engineering stress-strain curves were generated for each pillar, from which the elastic moduli and $0.2 \%$ offset yield stress were determined. Moduli and yield stresses for the ODS were reported in Ref. 18, and yield stresses for the $\mathrm{Cu}-24 \%$ Ta were reported in Ref. 20.

\section{Algorithm to automate true stress-strain calculation}

To calculate the true stress and strain, we developed an algorithm within Matlab ${ }^{\text {Ts }}$ to automate the measurement of 


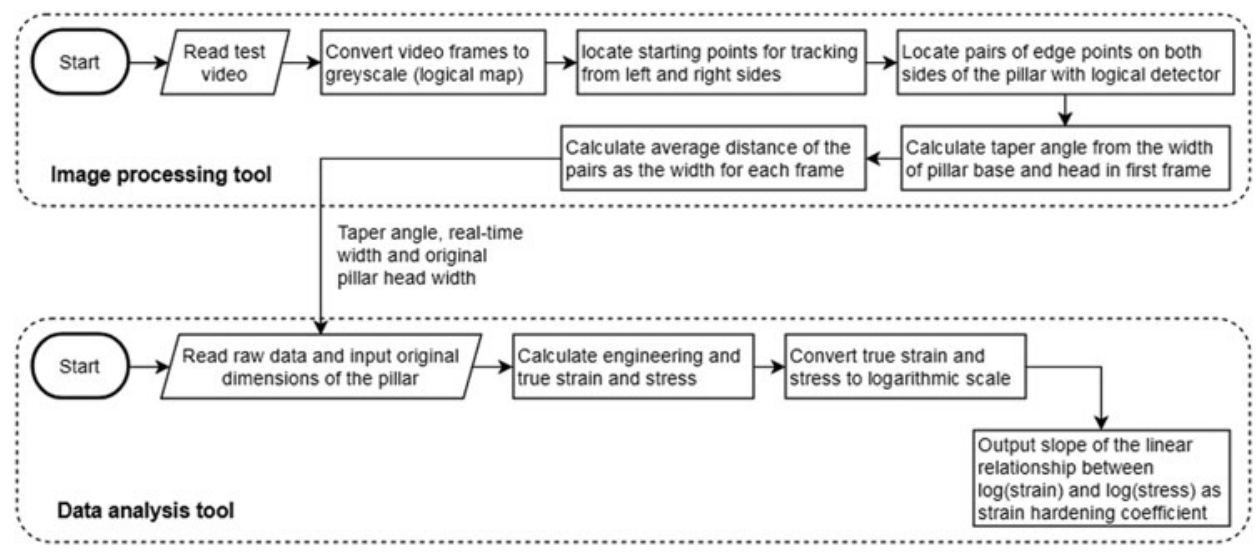

Figure 7: Flowchart of Matlab ${ }^{\text {TM }}$ algorithm developed to automate pillar width determination and true stress-strain curve calculation.

instantaneous pillar widths throughout the compression test. The algorithm was comprised of two major tools, executed in sequence: (i) image processing to determine pillar widths from TEM video, and (ii) data analysis to calculate true stress-strain curves. A flowchart of the algorithm is shown in Fig. 7.

Within the image processing tool, each frame of the TEM video was first converted to a greyscale image. The canny edge detection routine, built-in within Matlab ${ }^{\text {тx }}$, applied a Gaussian filter to the image; the derivative of the Gaussian filter was used to identify local maxima. These local maxima were edges or boundaries of features within the original TEM video frame. For the purposes of this study, these identified "edges" were the true edges of the pillar, as well as some of the highest-contrast features within the pillar microstructure (e.g., grain boundaries, precipitates, dislocation loops). Based on the edge identification, a pixel-by-pixel binary numerical map was generated, wherein pixels containing an identified edge were marked as 1 and are colored white, while all other pixels were marked as 0 and were colored black.

Once the pixels in each frame are color-coded, a logical filter is used to identify pillar dimensions. A logical filter moves downward from the top left and top right corners of the image to identify pixels surrounded by all black (or 0) pixels. These pixels are set as the starting points for the edge tracking algorithm and are marked as ' + ' in Fig. 8; these points ensure the pillar edge tracking begins in the TEM vacuum, rather than on the specimen or flat punch. From the starting points, the script moves toward the center of the image until it encounters pillar edges, marked as ' $X$ ' in Fig. 8. The script then moves onto each subsequent row of pixels in the binary numerical map and scans from both sides until it marks five or more points (based on user preference), or until it reaches the upper or lower boundary of the TEM vacuum. After five pairs of edge points are marked, the distance between each pair is calculated, and the average of these distances is exported as the instantaneous pillar width; this is repeated for each frame of the video. On

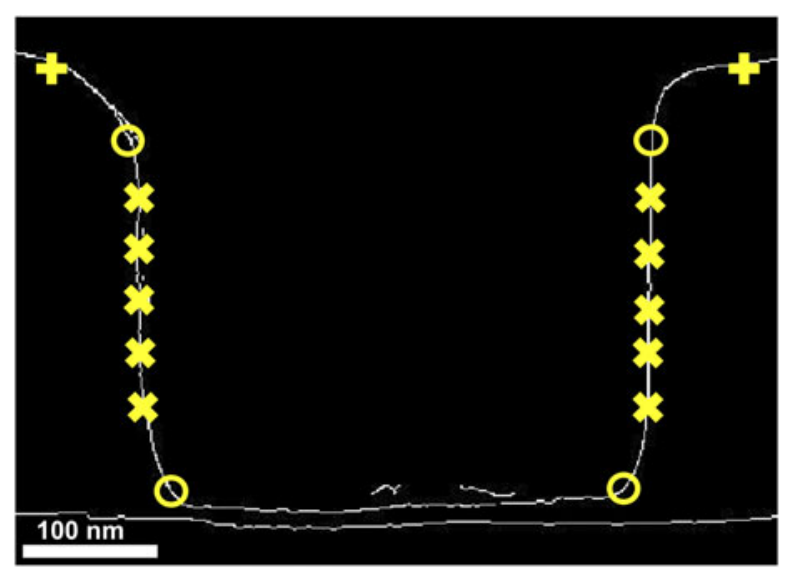

Figure 8: Application of edge tracking algorithm to a frame that has been converted to binary (black and white) image, with the starting points for the edge tracking algorithm marked ' + ', pillar edges marked ' $\times$ ', and pillar base and head marked ' $\bigcirc$ '.

only the first frame of the video, the pillar base and head (marked as 'o' in Fig. 8) widths are specifically measured for calculating taper angle as:

$$
\tan (\theta)=\frac{L_{\text {base }}-L_{\text {head }}}{2 h},
$$

where $L_{\text {base }}$ is the width of the pillar at contact with the substrate, $L_{\text {head }}$ is the pillar width at contact with the indentation head, and $h$ is the height of the pillar.

The second component of the script calculates true stress and strain hardening exponent. The raw load-displacement data obtained from the experiment is read in to Matlab ${ }^{\mathrm{Tw}}$. The user specifies the original pillar dimensions, and the instantaneous pillar widths (for each frame) are called from the image analysis portion of the script. Engineering stress and strain are first calculated based on original pillar dimensions, and the elastic modulus is determined. True stress and strain are calculated at each time step (i.e., in each frame), based on the instantaneous pillar dimensions and using expressions 
developed by Zhang et al. [96] for multicrystalline micropillars under compression:

$$
\begin{gathered}
\varepsilon_{\mathrm{T}}=\frac{1+\frac{L_{0}}{r_{\text {head }}} \tan (\theta)}{E_{\text {measured }}} \frac{P L_{\text {final }}}{A_{\text {half }} L_{0}}+\ln \left(\frac{L_{0}}{L_{\text {final }}}\right), \\
\sigma_{\mathrm{T}}=\frac{P}{A_{\text {half }} L_{0}}\left\{L_{0}-\left[u_{\text {tot }}-\frac{P \sqrt{\pi}\left(1-v^{2}\right)}{2 E_{\text {substrate }} \sqrt{A_{\text {base }}}}\right]\right\},
\end{gathered}
$$

where $L_{0}$ is the initial pillar height, $A_{\text {half }}$ is the pillar crosssectional area at half the initial pillar height, $L_{\text {final }}$ is the final pillar height, $r_{\text {head }}$ is the radius at the top of the pillar, $u_{\text {tot }}$ is the total displacement, and $A_{\text {base }}$ is the average cross-sectional area of the substrate. Although the compression pillars studied in this work have rectangular cross-sections, the automated method presented can be utilized on pillars with round crosssections and can also be extended to SEM in situ compression pillar testing.

\section{Acknowledgments}

This research was sponsored in part by the National Science Foundation CAREER award DMR-1752636, the US Department of Energy Office of Nuclear Energy awards DENE0008758 and DE-NE0008759, Purdue University, and by the US DOE Office of Nuclear Energy under DOE Idaho Operations Office contract DE-AC07-05ID14517, as part of the Nuclear Science User Facilities experiments 16-656 and 181168 .

\section{Supplementary material}

To view supplementary material for this article, please visit https://doi.org/10.1557/jmr.2019.295.

\section{References}

1. D. Kiener, A.M. Minor, O. Anderoglu, Y. Wang, S.A. Maloy, and P. Hosemann: Application of small-scale testing for investigation of ion-beam-irradiated materials. J. Mater. Res. 27, 2724 (2012)

2. P. Hosemann, C. Shin, and D. Kiener: Small scale mechanical testing of irradiated materials. J. Mater. Res. 30, 1231 (2015).

3. P. Hosemann: Small-scale mechanical testing on nuclear materials: Bridging the experimental length-scale gap. Scr. Mater. 143, 161 (2018).

4. E. Arzt: Size effects in materials due to microstructural and dimensional constraints: A comparative review. Acta Mater. 46, 5611 (1998)

5. W.D. Nix and H.J. Gao: Indentation size effects in crystalline materials: A law for strain gradient plasticity. J. Mech. Phys. Solids 46, 411 (1998).
6. A.A. Elmustafa and D.S. Stone: Indentation size effect in polycrystalline F.C.C. metals. Acta Mater. 50, 3641 (2002).

7. D. Kiener, W. Grosinger, G. Dehm, and R. Pippan: A further step towards an understanding of size-dependent crystal plasticity: In situ tension experiments of miniaturized single-crystal copper samples. Acta Mater. 56, 580 (2008).

8. J.D. Nowak, A.R. Beaber, O. Ugurlu, S.L. Girshick, and W.W. Gerberich: Small size strength dependence on dislocation nucleation. Scr. Mater. 62, 819 (2010).

9. J.R. Greer and J.T.M. De Hosson: Plasticity in small-sized metallic systems: Intrinsic versus extrinsic size effect. Prog. Mater. Sci. 56, 654 (2011).

10. A.H.W. Ngan, X.X. Chen, P.S.S. Leung, R. Gu, and K.F. Gan: Size effects of micrometer-scaled metals-The search continues for materials containing real microstructures. MRS Commun. 7, 131 (2017).

11. J.P. Wharry, K.H. Yano, and P.V. Patki: Intrinsic-extrinsic size effect relationship for micromechanical tests. Scr. Mater. 162, 63 (2019).

12. K.H. Yano, S. Thomas, M.J. Swenson, Y. Lu, and J.P. Wharry: TEM in situ cube-corner indentation analysis using ViBe motion detection algorithm. J. Nucl. Mater. 502, 201 (2018).

13. M.S. Ding, L. Tian, W.Z. Han, J. Li, E. Ma, and Z.W. Shan: Nanobubble fragmentation and bubble-free-channel shear localization in helium-irradiated submicron-sized copper. Phys. Rev. Lett. 117, 215501 (2016).

14. C. Chisholm: Quantitative In Situ TEM Studies of Small-Scale Plasticity in Irradiated and Unirradiated Metals (University of California, Berkeley, 2015).

15. W.Z. Han, M.S. Ding, and Z.W. Shan: Cracking behavior of helium-irradiated small-volume copper. Scr. Mater. 147, 1 (2018).

16. D. Kiener, P. Hosemann, S.A. Maloy, and A.M. Minor: In situ nanocompression testing of irradiated copper. Nat. Mater. 10, 608 (2011).

17. S. Mao, S. Özerinç, W.P. King, R.S. Averback, and S.J. Dillon: Effect of irradiation damage on the shear strength of $\mathrm{Cu}-\mathrm{Nb}$ interfaces. Scr. Mater. 90-91, 29 (2014)

18. K.H. Yano, M.J. Swenson, Y. Wu, and J.P. Wharry: TEM in situ micropillar compression tests of ion irradiated oxide dispersion strengthened alloy. J. Nucl. Mater. 483, 107 (2017).

19. G.S. Jawaharram, P.M. Price, C.M. Barr, K. Hattar,

R.S. Averback, and S.J. Dillon: High temperature irradiation induced creep in Ag nanopillars measured via in situ transmission electron microscopy. Scr. Mater. 148, 1 (2018).

20. P.V. Patki: Microstructure Evolution and TEM in situ Mechanical Testing of Proton Irradiated Nanocrystalline Copper Tantalum Alloy (Purdue University, West Lafayette, Indiana, 2018).

21. C. Gammer, M-I. Richard, and C. Eberl: Measurement of local strain. MRS Bull. 44, 459 (2019).

22. J.C. Kuo, S. Zaefferer, Z. Zhao, M. Winning, and D. Raabe: Deformation behavior of aluminum bicrystals. Adv. Eng. Mater. 5, 563 (2003). 
23. A. Godara, D. Raabe, I. Bergmann, R. Putz, and U. Muller: Influence of additives on the global mechanical behavior and the microscopic strain localization in wood reinforced polypropylene composites during tensile deformation investigated using digital image correlation. Compos. Sci. Technol. 69, 139 (2009).

24. M. Kamaya and M. Kawakubo: A procedure for determining the true stress-strain curve over a large range of strains using digital image correlation and finite element analysis. Mech. Mater. 43, 243 (2011).

25. F. Zhu, P. Bai, J. Zhang, D. Lei, and X. He: Measurement of true stress-strain curves and evolution of plastic zone of low carbon steel under uniaxial tension using digital image correlation. Opt. Lasers Eng. 65, 81 (2015).

26. D. Raabe, M. Sachtleber, Z. Zhao, F. Roters, and S. Zaefferer: Micromechanical and macromechanical effects in grain scale polycrystal plasticity experimentation and simulation. Acta Mater. 49, 3433 (2001).

27. L. Toualbi, C. Cayron, P. Olier, R. Logé, and Y. de Carlan:

Relationships between mechanical behavior and microstructural evolutions in Fe 9Cr-ODS during the fabrication route of SFR cladding tubes. J. Nucl. Mater. 442, 410 (2013).

28. C. Heintze, F. Bergner, and M. Hernández-Mayoral: Ionirradiation-induced damage in $\mathrm{Fe}-\mathrm{Cr}$ alloys characterized by nanoindentation. J. Nucl. Mater. 417, 980 (2011).

29. M. Ando, H. Tanigawa, S. Jitsukawa, T. Sawai, Y. Katoh, A. Kohyama, K. Nakamura, and H. Takeuchi: Evaluation of hardening behaviour of ion irradiated reduced activation ferritic/ martensitic steels by an ultra-micro-indentation technique. J. Nucl. Mater. 307-311, 260 (2002).

30. P. Hosemann, C. Vieh, R.R. Greco, S. Kabra, J.A. Valdez,

M.J. Cappiello, and S.A. Maloy: Nanoindentation on ion irradiated steels. J. Nucl. Mater. 389, 239 (2009).

31. J. Penisten: The Mechanism of Radiation-Induced Segregation in Ferritic-Martensitic Steels (University of Michigan, Ann Arbor, Michigan, 2012).

32. Y. Champion, S. Guérin-Mailly, J-L. Bonnentien, and

P. Langlois: Fabrication of bulk nanostructured materials from metallic nanopowders: Structure and mechanical behaviour. Scr. Mater. 44, 1609 (2001).

33. L. Philippe, Z. Wang, I. Peyrot, A.W. Hassel, and J. Michler: Nanomechanics of rhenium wires: Elastic modulus, yield strength and strain hardening. Acta Mater. 57, 4032 (2009).

34. I. Ovid'ko, C. Pande, and R. Masumura: Grain boundaries in nanomaterials. In Nanomaterials Handbook, Yury Gogotsi, ed. (CRC Press, Boca Raton, Florida, 2006); Ch. 18, p. 22-531.

35. K.A. Darling, M.A. Tschopp, R.K. Guduru, W.H. Yin, Q. Wei, and L.J. Kecskes: Microstructure and mechanical properties of bulk nanostructured $\mathrm{Cu}-\mathrm{Ta}$ alloys consolidated by equal channel angular extrusion. Acta Mater. 76, 168 (2014).

36. C.K. Dolph, D.J. da Silva, M.J. Swenson, and J.P. Wharry: Plastic zone size for nanoindentation of irradiated Fe-9\% Cr ODS. J. Nucl. Mater. 481, 33 (2016).
37. C. Robertson, B.K.K. Panigrahi, S. Balaji, S. Kataria, Y. Serruys, M-H.H. Mathon, and C.S.S. Sundar: Particle stability in model ODS steels irradiated up to $100 \mathrm{dpa}$ at $600{ }^{\circ} \mathrm{C}$ : TEM and nanoindentation investigation. J. Nucl. Mater. 426, 240 (2012).

38. G. Dehm, B.N.N. Jaya, R. Raghavan, and C. Kirchlechner: Overview on micro- and nanomechanical testing: New insights in interface plasticity and fracture at small length scales. Acta Mater. 142, 248 (2018).

39. D.J. Dunstan and A.J. Bushby: The scaling exponent in the size effect of small scale plastic deformation. Int. J. Plast. 40, 152 (2013).

40. D. Kiener and A.M. Minor: Source-controlled yield and hardening of $\mathrm{Cu}(100)$ studied by in situ transmission electron microscopy. Acta Mater. 59, 1328 (2011).

41. D.M. Dimiduk, C. Woodward, R. LeSar, and M.D. Uchic: Scalefree intermittent flow in crystal plasticity. Science 312, 1188 (2006).

42. A.S. Schneider, D. Kaufmann, B.G. Clark, C.P. Frick, P.A. Gruber, R. Mönig, O. Kraft, and E. Arzt: Correlation between critical temperature and strength of small-scale bcc pillars. Phys. Rev. Lett. 103, 1 (2009).

43. L. Jiang, J.J. Jonas, A.A. Luo, A.K. Sachdev, and S. Godet Twinning-induced softening in polycrystalline AM30 Mg alloy at moderate temperatures. Scr. Mater. 54, 771 (2006).

44. K. Farrell, T.S. Byun, and N. Hashimoto: Deformation mode maps for tensile deformation of neutron-irradiated structural alloys. J. Nucl. Mater. 335, 471 (2004).

45. N.R. Barton, A. Arsenlis, and J. Marian: A polycrystal plasticity model of strain localization in irradiated iron. J. Mech. Phys. Solids 61, 341 (2013)

46. T.H. Blewitt, R.R. Coltman, R.E. Jamison, and J.K. Redman: Radiation hardening of copper single crystals. J. Nucl. Mater. 2, 277 (1960).

47. J.L. Brimhall: The Effect of Neutron Irradiation on Sliplines in Molybdenum (BNWL-44) (Battelle Northwest Laboratories, Richland, Washington, 1965).

48. A. Okada, K. Kanao, T. Yoshiie, and S. Kojima: Transition of deformation structures in $\mathrm{Ni}$ and $\mathrm{Au}$ by D-T neutron irradiation. Mater. Trans. JIM 3, 265 (1989).

49. K.S. Choi, W.N. Liu, X. Sun, and M.A. Khaleel: Microstructurebased constitutive modeling of TRIP steel: Prediction of ductility and failure modes under different loading conditions. Acta Mater. 57, 2592 (2009).

50. C. Ritschel, A. Luft, and D. Schulze: On the change of dislocation structure during the postdeformation of cold worked molybdenum single crystals at elevated temperature. Krist. Tech. 13, 791 (1978).

51. S. Yoshida, M. Kiritani, Y. Deguchi, and N. Kamigaki Hardening and Recovery of Quenched Gold (Japan Institute of Metals, Aoba Aramaki, Sendai, 1968); p. 83.

52. A.H. Cottrell and R.J. Stokes: Effects of temperature on the plastic properties of aluminium crystals. Proc. R. Soc. Lond. Ser A Math. Phys. Sci. 233, 17 (1955).

53. T. Mori and M. Meshii: Plastic deformation of quench-hardened aluminum single crystals. Acta Metall. 17, 167 (1969). 
54. A. Gysler, G. Lütjering, and V. Gerold: Deformation behavior of age-hardened Ti-Mo alloys. Acta Metall. 22, 901 (1974).

55. G. Hahn: A model for yielding with special reference to the yieldpoint phenomena of iron and related bcc metals. Acta Metall. 10, 727 (1962).

56. B.N. Singh, A.J.E. Foreman, and H. Trinkaus: Radiation hardening revisited: Role of intracascade clustering. J. Nucl. Mater. 249, 103 (1997).

57. R. Price and A. Kelly: Deformation of age-hardened aluminium alloy crystals-I plastic flow. Acta Metall. 12, 159 (1964).

58. B. Bakó, D. Weygand, M. Samaras, J. Chen, M.A. Pouchon, P. Gumbsch, and W. Hoffelner: Discrete dislocation dynamics simulations of dislocation interactions with $\mathrm{Y}_{2} \mathrm{O}_{3}$ particles in PM2000 single crystals. Philos. Mag. 87, 3645 (2007).

59. C. Robertson and K. Gururaj: Plastic deformation of ferritic grains in presence of ODS particles and irradiation-induced defect clusters: A 3D dislocation dynamics simulation study. J. Nucl. Mater. 415, 167 (2011).

60. M.J. Swenson and J.P. Wharry: Nanocluster irradiation evolution in $\mathrm{Fe}-9 \% \mathrm{Cr}$ ODS and ferritic-martensitic alloys. J. Nucl. Mater 496, 24 (2017).

61. J.P. Wharry, M.J. Swenson, and K.H. Yano: A review of the irradiation evolution of dispersed oxide nanoparticles in the b.c.c. $\mathrm{Fe}-\mathrm{Cr}$ system: Current understanding and future directions. $J$. Nucl. Mater. 486, 11 (2017).

62. P. Dubuisson, R. Schill, M-P. Hugon, I. Grislin, and J-L. Seran: Behavior of an oxide dispersion strengthened ferritic steel irradiated in Phenix. In Effects of Radiation on Materials: 18th International Symposium ASTM STP 1325, R.K. Nanstad, M.L. Hamilton, F.A. Garner, and A.S. Kumar, eds. (American Society for Testing and Materials, West Conshohocken, Pennsylvania, 1999); p. 882.

63. M.L. Lescoat, J. Ribis, A. Gentils, O. Kaïtasov, Y. De Carlan, and A. Legris: In situ TEM study of the stability of nano-oxides in ODS steels under ion-irradiation. J. Nucl. Mater. 428, 176 (2012).

64. Y. Zhanbing, H. Benfu, H. Kinoshita, H. Takahashi, and S. Watanabe: Effect of hydrogen ion/electron dual-beam irradiation on microstructural damage of a 12Cr-ODS ferrite steel. J. Nucl. Mater. 398, 81 (2010).

65. L. Lu, X. Chen, X. Huang, and K. Lu: Revealing the maximum strength in nanotwinned copper. Science 323, 607 (2009).

66. Y.T. Zhu and X. Liao: Retaining ductility. Nat. Mater. 3, 351 (2004).

67. K. Kumar, H. Van Swygenhoven, and S. Suresh: Mechanical behavior of nanocrystalline metals and alloys. Acta Mater. 51, 5743 (2003).

68. X.L. Wu, Y.T. Zhu, Y.G. Wei, and Q. Wei: Strong strain hardening in nanocrystalline nickel. Phys. Rev. Lett. 103, 205504 (2009).

69. M. Chen, E. Ma, K.J. Hemker, H. Sheng, Y. Wang, and $X$. Cheng: Deformation twinning in nanocrystalline aluminum. Science 300, 1275 (2003).
70. J-Y. Zhang, G. Liu, R.H. Wang, J. Li, J. Sun, and E. Ma: Doubleinverse grain size dependence of deformation twinning in nanocrystalline Cu. Phys. Rev. B 81, 172104 (2010).

71. H. Van Swygenhoven, P.M. Derlet, and A.G. Frøseth: Nucleation and propagation of dislocations in nanocrystalline fcc metals. Acta Mater. 54, 1975 (2006).

72. V. Yamakov, D. Wolf, S.R. Phillpot, A.K. Mukherjee, and H. Gleiter: Deformation-mechanism map for nanocrystalline metals by molecular-dynamics simulation. Nat. Mater. 3, 43 (2004).

73. M.Y. Gutkin, I.A. Ovid'ko, and N.V. Skiba: Grain boundary sliding and lattice dislocation emission in nanocrystalline materials under plastic deformation. Phys. Solid State 47, 1662 (2005).

74. M. Yu, X.H. Peng, and P.H. Wen: Effect of cooperative grain boundary sliding and migration on dislocation emission from interface collinear crack tip in nanocrystalline bi-materials. Acta Mech. 229, 3901 (2018).

75. K.A. Padmanabhan, G.P. Dinda, H. Hahn, and H. Gleiter: Inverse Hall-Petch effect and grain boundary sliding controlled flow in nanocrystalline materials. Mater. Sci. Eng. A 452-453, 462 (2007)

76. D. Guo, S. Song, R. Luo, W.A. Goddard, M. Chen, K.M. Reddy, and Q. An: Grain boundary sliding and amorphization are responsible for the reverse Hall-Petch relation in superhard nanocrystalline boron carbide. Phys. Rev. Lett. 121, 145504 (2018).

77. M.G. Zelin and A.K. Mukherjee: Geometrical aspects of superplastic flow. Mater. Sci. Eng. A 208, 210 (1996).

78. L. Wang, J. Teng, P. Liu, A. Hirata, E. Ma, Z. Zhang, M. Chen, and $\mathrm{X}$. Han: Grain rotation mediated by grain boundary dislocations in nanocrystalline platinum. Nat. Commun. 5, 4402 (2014).

79. J. Schiotz: A maximum in the strength of nanocrystalline copper. Science 301, 1357 (2003).

80. H. Van Swygenhoven and P. Derlet: Grain-boundary sliding in nanocrystalline fcc metals. Phys. Rev. B 64, 224105 (2001).

81. J.W. Cahn and J.E. Taylor: A unified approach to motion of grain boundaries, relative tangential translation along grain boundaries, and grain rotation. Acta Mater. 52, 4887 (2004).

82. D. Wolf, V. Yamakov, S.R. Phillpot, A. Mukherjee, and H. Gleiter: Deformation of nanocrystalline materials by moleculardynamics simulation: Relationship to experiments? Acta Mater. 53, 1 (2005).

83. D. Farkas, S. Mohanty, and J. Monk: Strain-driven grain boundary motion in nanocrystalline materials. Mater. Sci. Eng. A 493, 33 (2008).

84. S.M. Han, M.A. Phillips, and W.D. Nix: Study of strain softening behavior of $\mathrm{Al}-\mathrm{Al}_{3} \mathrm{Sc}$ multilayers using microcompression testing. Acta Mater. 57, 4473 (2009).

85. N. Li, J. Wang, J.Y. Huang, A. Misra, and X. Zhang: In situ TEM observations of room temperature dislocation climb at interfaces in nanolayered Al/Nb composites. Scr. Mater. 63, 363 (2010).

86. J.Y. Zhang, S. Lei, Y. Liu, J.J. Niu, Y. Chen, G. Liu, X. Zhang, and J. Sun: Length scale-dependent deformation behavior of nanolayered Cu/Zr micropillars. Acta Mater. 60, 1610 (2012). 
87. N.A. Mara, D. Bhattacharyya, J.P. Hirth, P. Dickerson, and A. Misra: Mechanism for shear banding in nanolayered composites. Appl. Phys. Lett. 97, 021909 (2010).

88. N.A. Mara, D. Bhattacharyya, P. Dickerson, R.G. Hoagland, and A. Misra: Deformability of ultrahigh strength $5 \mathrm{~nm} \mathrm{Cu} / \mathrm{Nb}$ nanolayered composites. Appl. Phys. Lett. 92, 231901 (2008).

89. S. Ohtsuka, S. Ukai, M. Fujiwara, T. Kaito, and T. Narita: Improvement of creep strength of 9CrODS martensitic steel by controlling excess oxygen and titanium concentrations. Mater. Trans. 46, 487 (2005).

90. R.E. Stoller, M.B. Toloczko, G.S. Was, A.G. Certain, S. Dwaraknath, and F.A. Garner: On the use of SRIM for computing radiation damage exposure. Nucl. Instrum. Methods Phys. Res. Sect. B Beam Interact. Mater. Atoms 310, 75 (2013).

91. S.J. Zinkle and L.L. Snead: Opportunities and limitations for ion beams in radiation effects studies: Bridging critical gaps between charged particle and neutron irradiations. Scr. Mater. 143, 154 (2017).
92. M.J. Swenson and J.P. Wharry: The comparison of microstructure and nanocluster evolution in proton and neutron irradiated $\mathrm{Fe}-9 \%$ Cr ODS steel to $3 \mathrm{dpa}$ at $500{ }^{\circ} \mathrm{C}$. J. Nucl. Mater. 467, 97 (2015).

93. M.J. Swenson and J.P. Wharry: TEM characterization of irradiated microstructure of $\mathrm{Fe}-9 \% \mathrm{Cr}$ ODS and ferriticmartensitic alloys. J. Nucl. Mater. 502, 30 (2018).

94. Y. Bazarbayev, M. Kattoura, K.S. Mao, J. Song, V.K. Vasudevan, and J.P. Wharry: Effects of corrosion-inhibiting surface treatments on irradiated microstructure development in Ni-base alloy 718. J. Nucl. Mater. 512, 276 (2018).

95. M.B. Lowry, D. Kiener, M.M. Leblanc, C. Chisholm, J.N. Florando, J.W. Morris, and A.M. Minor: Achieving the ideal strength in annealed molybdenum nanopillars. Acta Mater. 58, 5160 (2010).

96. J.Y. Zhang, X. Liang, P. Zhang, K. Wu, G. Liu, and J. Sun: Emergence of external size effects in the bulk-scale polycrystal to small-scale single-crystal transition: A maximum in the strength and strain-rate sensitivity of multicrystalline $\mathrm{Cu}$ micropillars. Acta Mater. 66, 302 (2014). 